\title{
El ideal de madre en el siglo XXI. La representa- ción de la maternidad en las revistas de familia
}

\author{
Pilar MEdinA BRAVO \\ Universitat Pompeu Fabra \\ pilar.medina@upf.edu \\ Mònica Figueras-MAZ \\ Universitat Pompeu Fabra \\ monica.figueras@upf.edu \\ Lorena GóMEZ-PUERTAS \\ Universitat Pompeu Fabra \\ lorena.gomez@upf.edu
}

Recibido: 13 de junio de 2013

Aceptado: 10 de octubre de 2013

\section{Resumen}

El trabajo analiza de qué manera las revistas dedicadas a los temas de embarazo, parto y crianza ahondan en el modelo de «maternidad intensiva» de Hays (1998). Según la autora, este ideal de perfección maternal representa un gran el peso emocional porque deposita la tarea de la crianza en la mujer-madre. En el artículo se concretan las características del modelo y se analiza su presencia en las secciones de expertos de las tres revistas familiares de mayor consumo en España (Mi bebé y yo, Ser padres. La revista del bebé y la familia, y El mundo de tu bebé). Para descubrir las estructuras narrativas predominantes, el análisis del discurso se basa en la caracterización y jerarquización de los protagonistas a partir de los roles actanciales ejercidos (madres, padres, bebés y expertos).

Palabras clave: maternidad, revistas de familia, estereotipos de género, bebés.

\section{The ideal mother in the XXI century. The representation of motherhood in family magazines}

\begin{abstract}
This paper analyzes how those magazines devoted to the issues of pregnancy, childbirth and parenting delve into the model of «intensive motherhood» (Hays, 1998). According to Hays, this ideal of perfection is a major maternal emotional burden because it places the challenge of raising the woman-mother. In this article we specify the main characteristics of the model and analyze its presence in the expert sections of the three most selling family magazines in Spain (Mi bebé y yo, Ser padres. La revista del bebé $y$ la familia, and El mundo de tu bebé). To uncover the dominant narrative structures, we analyze discourse by means of narrative semiotics, defining the actatial roles played by the characters (mothers, fathers, babies and experts).
\end{abstract}

Keywords: motherhood, family magazines, gender stereotypes, babies.

\section{Referencia normalizada}

MEDINA BRAVO, Pilar; FIGUERAS-MAZ, Mònica; y GÓMEZ-PUERTAS, Lorena (2014): "El ideal de madre en el siglo XXI. La representación de la maternidad en las revistas de familia". Estudios sobre el Mensaje Periodístico. Vol. 20, Núm. 1 (enero-junio), págs.: 487-504. Madrid, Servicio de Publicaciones de la Universidad Complutense.

Sumario: 1. Introducción. 2. La paradoja de la maternidad. 3. Objetivos y metodología. 4. Resultados. 5. Discusión y Conclusiones. 6. Referencias bibliográficas. 


\section{Introducción}

Hablar de «maternidad» en los medios comunicación puede parecer una cuestión trivial, pero como defienden Beck y Beck-Gernsheim (2003), son precisamente los procesos triviales los que hacen la historia y la sociedad. El análisis del modelo de maternidad imperante en la sociedad occidental nos obliga a revisar las características del grupo familiar, la progresiva individualización del sujeto-mujer, y las tensiones inevitables entre una economía de mercado y el deseo de consolidar lazos afectivos y cómo ello se refleja en las llamadas revistas familiares.

¿Los temas tratados per las revistas familiares son aquellos propios de la familia? ¿Los editores y redactores crean e imponen temáticas a las lectoras, o bien, son las lectoras las que deciden los contenidos con la acción de compra/lectura? Más bien se trata de un acuerdo entre las dos partes sobre el significado de lo que es ser madre en nuestra sociedad; significado consensuado gracias al proceso de socialización en el que las preocupaciones e intereses de las madres son construidos. La prensa familiar es socializadora simplemente en la medida que recoge todos aquellos temas que deben formar parte del interés de las madres y, a la vez, fija normas de conducta y modelos que hay que seguir. En este sentido la prensa familiar se puede equiparar a la femenina, mucho más investigada. La angustia por el perfecto cuidado del bebé mantiene a las madres durante la época de la primera crianza al margen de lo que pasa en otras esferas de la vida, especialmente la pública, de forma que como hacía la prensa femenina, facilita que se puedan "concentrar en exclusiva en sus deberes de ama de casa del hogar" (Segura \& Selva, 1984: 89). Los temas que hoy tratan las revistas objeto de estudio estaban incluidos en las revistas femeninas como una más de las obligaciones de la mujer:

Las noticias de las exigencias de la moda o de las prescripciones higiénicas, consejos de belleza, cuidados maternales, etc. se dan en forma persuasiva. Sin embargo, atenuada, ya sea porque adoptan uno estilo epistolar o un aire de susurro confidencial, ya sea porque destilan un tono de complicidad femenil que disimula la distancia que este tipo de mensaje postula (Perinat \& Marrades, 1980: 74).

Desde Grecia hasta nuestros días ha existido la separación entre espacio público y espacio privado. La aparición de la prensa femenina no fue una cuestión ingenua ideológicamente sino que se adeuda al proyecto ilustrado de la educación. A finales del XVIII la prensa transmite instrucciones formativas a cada tipo de público: la de información general se erige como propia de los hombres y la femenina, propia de las mujeres (Figueras, 2005).

Una prensa femenina que nacerá para mostrar la casa del padre o del marido -la mujer no tiene casa- en la que las mujeres son representadas ejecutando sus deberes. Si no se ciñe a estos deberes -que suponen 'todo lo que tiene que hacer en este mundo'-, la prensa de referencia en su proceso de legitimación de lo que las élites dominantes dicen, expulsará de la realidad comunicativa cualquier otro deber que las mujeres se autoimpongan. Será la prensa femenina la que registrará de modo recurrente cuáles son los deberes del género (Fagoaga, 1985: 131).

De este modo, cada tipo de prensa refuerza el lugar de cada sexo en la sociedad, se aparta a las mujeres de la prensa de información general, y, a la vez, se les crea un lugar 
que redunda en la reproducción de sus roles (Abril, en Ortega, 1995). Hay que esperar a la década de los noventa a que aparezcan las revistas familiares, escindiéndose esta temática de las revistas femeninas. En la medida que el cuidado de bebé se va convirtiendo en un negocio incipiente, empiezan a proliferar cabeceras que, además de quioscos, se distribuyen en hospitales o centros de pediatría, muchas de ellas gratuitas y con una finalidad claramente comercial, dado que van cargadas de anuncios.

En la actualidad, la institución familiar se ha convertido en algo más complejo y controvertido de lo que lo fue en el pasado. Ya sea por la incertidumbre sobre el papel y normas en la crianza; por el volumen de separaciones y divorcios y el aumento de familias reconstituidas; por las técnicas de reproducción asistida...Da la impresión de que el círculo familiar es el depositario de gran parte de las aspiraciones y conflictos de los individuos del siglo XXI. Así, la imagen que la sociedad postindustrial construye de la institución familiar resulta cada vez más poliédrica, a la manera de "comunidades a tiempo parcial" (Beck-Gernsheim, 2003). La familia ha pasado a estar en el ojo del huracán: exaltado refugio ante la frialdad del individualismo más descarnado a la vez que fuente de desdichas personales. Lejos queda aquella imagen monolítica de la foto de familia. Tener un puerto seguro al que volver siempre es tranquilizador, así que puede entenderse la reivindicación de muchos actores sociales por el retorno de una imagen idealizada de la familia del pasado.

Resulta urgente reivindicar cómo uno de los mayores peligros que atenazan a cualquier formato de familia no es la inmadurez de sus miembros sino la asimilación de sus miembros a sujetos de consumo (Castilla, 2009) en una progresiva mercantilización de la vida íntima (Hochschild, 2008). Este análisis de la subordinación a la lógica del sistema económico capitalista, se materializa en las relaciones entre madres e hijos:

Estas formas de subordinar a las mujeres benefician no sólo a los hombres sino también al capitalismo y al Estado moderno [...]. La relación entre madre e hijo sigue simbolizando, de manera realista o no, la oposición a las relaciones sociales basadas en la búsqueda competitiva de ganancia individual en un sistema de relaciones contractuales impersonales...Afirmo que la maternidad es uno de los terrenos centrales en los cuales se juega esta ambivalencia (Hays, 1998: 44).

La maternidad acaba siendo el escenario social en el que se desarrolla una nueva paradoja: de una parte, la posibilidad de una vivencia gratificante al participar del desarrollo de los hijos y, de otra, la subordinación a un discurso hegemónico por el que la madre es la depositaria principal y última de este desarrollo. Es así como podemos concluir que en el siglo XXI se ha consolidado el ideal de «buena madre» entendiendo por tal a aquella mujer capaz de brindar a su retoño un ambiente de satisfacción y tranquilidad emocional casi perfectos. El marco ideológico en el que se enmarca el ideal de madre enfatiza la importancia de que el hijo no sufra frustraciones ni emociones negativas, de manera que para ser una «buena» madre hay que enfrentase a una tarea altamente exigente y agotadora a nivel emocional (Viñas, 2003).

Por todo ello, el presente trabajo tiene como objetivo principal analizar el modelo cultural de esta «buena madre» presente en las revistas familiares de mayor consumo en España. 


\section{La paradoja de la maternidad}

La familia, entendida como institución-concha (Giddens, 2000), está obligada a incorporar nuevas conceptualizaciones, impensables en décadas anteriores. Ahora que la comunidad y la tradición han cedido terreno a la elección personal y a la construcción de biografías auto-planificadas (Beck \& Beck-Gernsheim, 1990), también han aumentado los niveles de incertidumbre y ambivalencia. Las tensiones que se generan en el ámbito de la familia o la pareja pueden entenderse como auténticos campos de batalla en los que se enfrentan tradición y modernidad. La invención de la experiencia de la «maternidad» como construcción cultural sobrepuesta a la situación biológica de quedarse embarazada, parir y alimentar es, precisamente, uno de estos campos de batalla en los que aparece mayor desigualdad afectiva entre hombres y mujeres (Giddens, 2000). Esta nueva ideología se acabará consolidando como modelo de identidad de toda mujer y servirá de justificante para apartarla de la vida y las decisiones públicas, auténticos ejes del poder. Para conseguirlo se reforzará la imagen de la bondad de la mujer-maternal como el prototipo social a seguir, siendo muchas las mujeres que (re)fuercen la idealización de la mujer-madre y asocien la maternidad a la feminidad auténtica a través del énfasis en la idea del «instinto maternal» (Badinter, 2011). El paso a la sociedad moderna implicará el «descubrimiento» de la infancia como un grupo social que precisa de atención y cuidados específicos. La Ilustración incorpora nuevas tareas y deberes para padres y madres al responsabilizar a éstos de la importante misión de preparar y educar a sus hijos como sujetos de derechos inalienables. Poco a poco, se empieza cada vez más a valorar la maternidad, y el cariño invade la relación madre-hijo. Hacia la segunda mitad del siglo XIX, la crianza infantil se asimila a la imagen de maternidad y de un sentimentalismo generalizado de pureza, piedad y patriotismo (Beck-Gernsheim, 2003; Hays, 1998) bajo el aura de todo un movimiento de concienciación principalmente dirigido a las mujeres proletarias para que incorporen los nuevos avances sanitarios, psicológicos y educativos en la crianza de su prole. Se instaura la idea de las madres como guardianas de la moral (es la época del dicho «hogar, dulce hogar»). El niño pasa a convertirse en "una especie de meta de una serie polifacética de esfuerzos" (Beck-Gernsheim, 2003: 169), en los que la madre se convierte en protagonista principal.

En este escenario, la experiencia de ser madre ha pasado a ser para muchas mujeres una decisión voluntaria y una experiencia reflexiva (Castilla, 2009). La nueva maternidad ya no es un destino sino una aparente decisión libre, en la que rápidamente surge un listado de preguntas a responder(se) tales como el número de hijos que se quiere tener, si se quiere (o no) un diagnóstico prenatal, o si la adopción o la fecundación asistida son vías a pensar. Las alegrías en la parentalidad conviven en estrecho margen de maniobra con la tensión que genera tomar tantas decisiones. Si bien es cierto que la tecnificación del hogar ha facilitado muchas de las cargas del hogar, no es menos cierto que ha aparecido un discurso social de enorme exigencia para la madre. El proceso de crianza es todo un ejercicio de responsabilidad materna, dirigido a conseguir la maduración óptima de los recursos potenciales de su hijo, así como la superación (también óptima) de sus defectos. 
Diferentes autores (p.e., Badinter, 2011; Beck-Gernsheim, 2003; Hays, 1998) coinciden en advertir de qué manera el nuevo discurso sobre la maternidad responde a una continua presión a la disponibilidad continua, optimización de las propias posibilidades y uso del conocimiento científico disponible. Para Hays:

La ideología pública de la correcta crianza infantil ha urgido a las madres a quedarse en casa con sus hijos, manteniendo así la coherencia entre la crianza por parte de las mujeres y su comportamiento abnegado [...] Y, sin embargo, esta forma de maternidad no es ni natural por sí misma ni, en un sentido absoluto, necesaria; es una construcción social. En otros tiempos y lugares, métodos más sencillos, que consumen menos tiempo y energía, se han considerado adecuados, y la madre no ha sido siempre y en todas partes la principal encargada de cuidar al niño. La idea de que la correcta crianza infantil exige no sólo de grandes cantidades de dinero sino también habilidades de nivel profesional y copiosas cantidades de energía física, moral, mental y emocional por parte de la madre individual es un fenómeno histórico relativamente reciente [...] Las modernas madres norteamericanas hacen mucho más que simplemente alimentar, cambiar y proteger a sus hijos hasta los seis años (Hays, 1998: 24).

Así pues -y siguiendo a la autora norteamericana- el modelo occidental de lo que se entiende por un ejercicio de maternidad responsable pivota en tres ejes principales:

- La crianza de los hijos es tarea fundamental de las madres

- Los métodos y consejos recomendados se centran en el bebé y en el niño

- Los métodos y consejos son elaborados por expertos, precisan de un considerable e intensivo gasto de energía emocional, y suponen un alto coste económico.

Este modelo cultural se basa en la idea de entender la maternidad como un ejercicio intensivo. Resulta paradójico que esta ideología se enmarca precisamente en una economía de mercado que se caracteriza por la competitividad y el individualismo autosuficiente. Además, conviene remarcar que estamos haciendo referencia al «modelo cultural» y no a las prácticas reales de las madres reales. Sin embargo, es fácil entender la fuerza que los discursos sociales tienen a la hora de plantear, defender, rechazar y/o valorar las conductas individuales.

En una terminología propia de la economía de mercado, la imagen resultante es la de una madre eficiente y eficaz, a la vez que amorosamente siempre disponible, lo que resulta paradójico (Hochschild, 2008). Isabel Aler advierte:

Si bien es cierto que lo mejor para la madre puede ser circunstancialmente la opción más propia para la criatura [...], eso no implica que todo vale lo mismo para el pleno bienestar presente y futuro de la criatura humana. Así, las ideas expertas sobre las pautas de crianza y socialización que van haciéndose dominantes al servicio de las reglas del mercado de trabajo y de consumo [...] son engañosas cuando se presentan como lo que no son (mejoras en la calidad de la crianza) y se oculta lo que realmente son (mejoras para la adaptación del adulto de hoy y de mañana al mercado capitalista de trabajo y del consumo) (Aler, 2006: 36).

\section{Objetivos y metodología}

El presente estudio se propone analizar la vigencia en el discurso de las revistas familiares del modelo de maternidad intensiva estudiado por Hays hace ya más de una 
década en la sociedad norteamericana y detallado en el apartado anterior. En concreto, el presente estudio se centra en el análisis de las estructuras narrativas de los mensajes y consejos elaborados por expertos.

Para la realización de nuestro estudio, hemos tomado como muestra los números publicados en junio y octubre de 2011 de Mi bebé y yo, Ser padres. La revista del bebé y la familia y El mundo de tu bebé por tratarse de publicaciones dedicadas al bebé y la familia de mayor consumo en España.

Mi bebé y yo (Sfera Editores España, S.L.), con 866.000 lectores al mes, según datos del Estudio General de Medios (EGM) en el periodo analizado (febrero-noviembre 2011) y, según datos de la Oficina General para la Difusión (OJD), 247.890 ejemplares promedio de tirada y 219.376 , promedio difusión en el periodo enero-diciembre de 2011.

Ser padres (G Y J España ediciones SL) tiene 452.000 lectores según el EGM y un promedio de tirada de 131.888 y de difusión de 106.984 ejemplares según OJD en los mismos periodos anteriores.

El mundo de tu bebé (RBA revistas) no consta en el EGM y según OJD su promedio de tirada es de 72.789 ejemplares y de difusión, de 61.462, también en los mismos periodos que las anteriores revistas.

Todas ellas presentan una estructura de contenidos diferente y para los objetivos del estudio nos hemos centrado en las secciones que recogen la voz del experto en cuestiones vinculadas al bebé. Así, el apartado de resultados recoge los datos obtenidos del análisis de todos los artículos de la sección de "Bebé (salud y cuidados)" de la revista El mundo de tu bebé; la sección de "Cuidados del bebé sano y feliz" de la revista Ser padres. La revista del bebé y la familia; y la sección de "Cuidados del bebé. Educación y crianza" de la revista Mi bebé y yo:

Para el análisis del discurso propuesto por las revistas familiares en torno a los modelos de maternidad, se ha implementado un diseño metodológico basado en los estudios más recientes sobre representación, identidad y construcción de imagen de individuos y/o colectivos en el campo de la comunicación desde la perspectiva interdisciplinar que integra la sociosemiótica, la narratología y la lingüística (p.e. Beaugrande \& Dressler, 1997; Courtés, 1997; Fairclough, 2003; Titscher, Meyer \& Vetter, 2000). En su planteamiento inicial combina el análisis de las estructuras semionarrativas desde un punto de vista abstracto con el análisis pragmático del plano de la enunciación y los aspectos de intencionalidad y aceptabilidad del texto que lo definen como acto comunicativo.

De este modo se analizan, en primer lugar, los roles actanciales ejercidos por los protagonistas de las narrativas (principalmente padres, bebés y expertos), de acuerdo al protocolo de caracterización y jerarquización de personajes y temas de Ruiz Collantes et al (2011). El diseño, de clara inspiración greimasiana (Greimas, 1990), se estructura en tres ejes: a) definición de las características del personaje (rasgos físicos y temperamentales), b) definición de las acciones (motivaciones, capacidades necesarias para llevarlas a cabo y tipología), y c) imagen del personaje en función del rol narrativo que cumple. A efectos de los resultados expuestos en este artículo, véase en la Figura 1 la definición de los elementos analizados. 
Tabla 1. Modelo de análisis para la caracterización y jerarquización de personajes en torno al tema de la maternidad

\begin{tabular}{|c|c|c|c|}
\hline $\begin{array}{l}\text { Roles actanciales } \\
\text { (madre/padre/padres/ } \\
\text { bebé/experto/otros: } \\
\text { figurativo/abstracto) }\end{array}$ & $\begin{array}{c}\text { Competencias } \\
\text { (si/no, explícitas o } \\
\text { implícitas) }\end{array}$ & Tipo de acción & $\begin{array}{l}\text { Manipulación } \\
\text { contractual }\end{array}$ \\
\hline 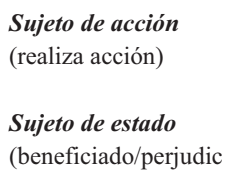 & $\begin{array}{l}\text { Querer } \\
\text { Deber } \\
\text { Poder } \\
\text { Saber }\end{array}$ & $\begin{array}{l}\text { Material- } \\
\text { somática } \\
\text { Cognitiva } \\
\text { Comunicativa } \\
{[\ldots]}\end{array}$ & $\begin{array}{l}\text { Promesa } \\
\text { Amenaza } \\
\text { Seducción } \\
\text { Provocación }\end{array}$ \\
\hline ado por la acción & Motivaciones & Propósito & Sanción \\
\hline $\begin{array}{l}\text { realizada) } \\
\text { Ayudante } \\
\text { Oponente }\end{array}$ & Pasiones y creencias & $\begin{array}{l}\text { Ganar objeto } \\
\text { Perder objeto } \\
\text { Mantener la } \\
\text { posesión } \\
\text { Mantener la } \\
\text { carencia }\end{array}$ & $\begin{array}{l}\text { Reconocimiento } \\
\text { (positivo/negativo) } \\
\text { Retribución } \\
\text { (premio/castigo) }\end{array}$ \\
\hline $\begin{array}{l}\text { Destinador contrato } \\
\text { (demanda acción) }\end{array}$ & Objeto de valor & Estado final & $\begin{array}{c}\text { Resultado de la } \\
\text { acción }\end{array}$ \\
\hline $\begin{array}{l}\text { Destinador sanción } \\
\text { (evalúa resultado) }\end{array}$ & $\begin{array}{l}\text { Vivencial/existencial } \\
\text { Social/económico } \\
\text { Ético/político } \\
\text { Pasional } \\
\text { Cognitivo }\end{array}$ & $\begin{array}{l}\text { Conjunción } \\
\text { Disyunción }\end{array}$ & $\begin{array}{l}\text { Éxito } \\
\text { Fracaso }\end{array}$ \\
\hline
\end{tabular}

En el plano de la enunciación, hemos centrado el análisis, por un lado, en las figuras del enunciador y narrador delegado (diferenciando a la revista del experto u otros individuos o instituciones), y por otro, en el enunciatario y/o narratario construido por el texto (madre, padre, o ambos indistintamente).

Por último, se han observado aquellas marcas estilísticas que permiten inferir la intencionalidad, esto es, la actitud del productor textual en torno a la meta específica que pretende conseguir, y la accesibilidad o actitud reclamada al receptor para percibir el texto como relevante y cooperar en la consecución de la meta discursiva propuesta. En último extremo, la suma de estas variables analíticas permite visibilizar el tipo de acto de habla construido en el discurso de las diferentes revistas familiares analizadas en torno al concepto de maternidad (ver Figura 2).

Tabla 2. Tipología de actos ilocutivos (ver Pericot, 2002)

\begin{tabular}{|c|c|c|}
\hline Tipo & Definición & Términos asociados \\
\hline ASERTIVO & $\begin{array}{l}\text { El enunciador afirma con seguridad la veracidad de lo que } \\
\text { comunica }\end{array}$ & Informa, afirma, describe \\
\hline DIRECTIVO & $\begin{array}{l}\text { El enunciador intenta que el enunciatario cumpla alguna } \\
\text { acción }\end{array}$ & $\begin{array}{l}\text { Ordena, obliga, demanda, sugiere, } \\
\text { insinúa, amenaza }\end{array}$ \\
\hline COMISIVO & El enunciador se compromete a cumplir una acción & Promete, se compromete \\
\hline EXPRESIVO & $\begin{array}{l}\text { El enunciador expresa una opinión o sentimientos hacia un } \\
\text { hecho o acción }\end{array}$ & $\begin{array}{l}\text { Denuncia, deplora, reprocha, } \\
\text { felicita, alaba, agradece, excusa }\end{array}$ \\
\hline DECLARACIONAL & $\begin{array}{l}\text { El enunciador pretende provocar un cambio en el mundo. } \\
\text { Ajusta la realidad al enunciado que actúa sobre ella }\end{array}$ & Declara, condena, jura \\
\hline
\end{tabular}




\section{Resultados}

La evaluación global de los textos analizados nos permite detectar cuáles son las estructuras semionarrativas predominantes en torno al modelo de maternidad de las revistas familiares analizadas.

Así, destaca una narrativa prototípica de base, en la que (1) 'el experto orienta, prescribe y/o sanciona a los padres en el cuidado del bebé' donde la revista se presenta como una plataforma de acceso a los expertos que pueden informar o sugerir las prácticas y conductas adecuadas (rol de destinador contrato y/o ayudante) para la crianza del bebé a unos padres - esencialmente la madre- que se presentan como sujetos de acción no competentes. Las narrativas parten, casi en su totalidad, de la imagen de los padres como sujetos que carecen especialmente de los conocimientos necesarios, movidos por temores e inseguridades sobre su propia capacidad, y que pierden la paciencia o no respetan las necesidades del pequeño porque no confían en su instinto de supervivencia.

Las competencias que suelen asociarse a la madre son de tipo fisiológico (características del útero materno, lactancia materna) o se presentan como naturales (el instinto maternal). Su objetivo es garantizar el bienestar físico y emocional del pequeño (sujeto de estado). Eventualmente el experto valora anticipadamente los resultados de las acciones de los padres, especialmente aquellas consideradas perjudiciales (destinador sanción: reconocimiento negativo) y completa la manipulación contractual basada en la amenaza.

Esta narrativa principal se completa con cuatro variables, según los padres sean sujetos de acción y a su vez, de estado, esto es, (a) beneficiados o (b) perjudicados en su acción de cuidar del bebé, o se especifiquen posibles (c) ayudantes u (d) oponentes de los progenitores en esta tarea. Así, en algunas tramas, los padres se definen como receptores de un beneficio vivencial o pasional, al disfrutar del placer de criar al pequeño y la ternura y alegría que desprende la convivencia familiar en esta etapa. Por el contrario, en raras ocasiones se incide en los posibles perjuicios que puedan padecer los padres al emprender la misión de cuidar al bebé. Se evitan términos como sacrificio o renuncia a actividades y placeres asociadas a otros ámbitos de la vida personal y/o profesional, y tan sólo se hace alusión explícita a pequeñas molestias asociadas a la cohabitación con un pequeño en pleno proceso de aprendizaje y experimentación (los ruidos en el hogar).

Al preguntarse con qué aliados cuentan los padres para la misión de crianza y educación del bebé, la respuesta es múltiple. Entre ellos, la revista sitúa reiteradamente: al propio bebé, como poseedor de un instinto natural de supervivencia, y a la industria, como proveedora de productos varios que facilitan la alimentación, la higiene y el desarrollo del pequeño. Obviamente, el experto con el que la revista establece contacto ejerce el rol de ayudante por antonomasia. Y tan sólo eventualmente se da margen a la experiencia de otros padres como fuente de conocimiento válida. Y ¿qué o quiénes obstaculizan la correcta crianza y educación de los hijos? La sociedad y los conocidos se definen como oponentes prototípicos. Una construcción que pone de manifiesto, por un lado, la necesidad de profesionalizar el asesoramiento a la maternidad de este tipo de publicaciones especializadas, y por otro lado, la preeminencia del 
conocimiento científico que llega a desacreditar a las tradicionales instituciones de socialización -familia y redes sociales- y reduce la experiencia compartida a mitos y creencias populares sin fundamento, cuando no peligrosos.

Además de esta estructura sociosemiótica predominante, se genera una segunda narrativa prototípica como alternativa, a menudo integrada con la primera en textos de mayor complejidad. (2) 'El bebé posee el instinto de supervivencia necesario para desarrollarse, pero depende de sus padres que logre convertirse en un individuo pleno' presenta al bebé como un sujeto de acción que es (o será en un plazo relativamente breve) competente para alcanzar diversos hitos del desarrollo humano (como por ejemplo, comer solo o caminar). El rol al que se delega a la madre es el de ayudante u oponente, según su capacidad de contribuir u obstaculizar esta evolución natural del pequeño. El experto mantiene su función de tutela sobre la figura materna (destinador contrato) con el objetivo de evitar que, por mala praxis, perjudique al pequeño (especialmente en el plano emocional al intentar forzar el desarrollo psicomotriz o de lenguaje). Emerge aquí con claridad la sumisión de los padres a un objetivo último e incuestionable: el de garantizar la felicidad del pequeño (no tan sólo como estado anímico a mantener, sino como resultado del correcto desarrollo psicológico del menor a lograr: potenciar su autoestima y su autonomía).

Por último, se detectan tres estructuras semionarrativas complementarias, con una incidencia menor en el discurso de las revistas analizadas que sintetizamos a continuación.

(3) 'La sumisión de los padres a las demandas del bebé: deber y compensación, las claves de la felicidad'. Se trata de una variación sobre la narrativa prototípica dominante en la que la revista se sitúa como ayudante de la madre (sujeto de acción) y el bebé triplica sus roles como destinador contrato y sujeto de estado, además de como posible oponente. El texto plantea las demandas del pequeño a la madre o bien como necesidades que la madre puede consentir y generan un beneficio emocional tanto para el bebé como para la progenitora, o bien como caprichos del bebé que no puede ni debe satisfacer por el riesgo que conllevan. Cuando se tipifican como caprichos, el bebé se infiere como oponente puesto que trata de impedir u obstaculizar la misión de la madre en tanto que salvaguardar su integridad física. Lo más curioso del texto es que en ningún momento incide en la incompetencia, al menos en el plano cognitivo, del bebé, sino que simplemente centra la atención en la responsabilidad de la madre, y continúa manteniendo como objetivo último el bienestar emocional del pequeño al que "debe compensar" la insatisfacción de no conseguir lo que pide.

(4) 'Cuando los padres perjudican al bebé: el especialista médico como recurso necesario' es otra de las narrativas secundarias que emergen, a menudo de manera inferida y combinada, y en contadas ocasiones como relato autónomo y explícito. En ella se sitúa a los padres como oponentes del especialista médico en tanto que sujeto de acción competente. Se trata de textos en torno a temas de salud, donde las enfermedades, síndromes o discapacidades se presentan como antisujetos de acción que pueden generar graves perjuicios al bebé. De nuevo la falta de formación específica de los padres los define como sujetos incompetentes cognitivamente: no reconocen los síntomas que permitirían una detección precoz del problema y su correcto tratamiento. 
Al no recurrir al personal sanitario cualificado (pediatras, oculistas, etc.), es decir, al no asumir el rol de destinadores-contrato que demanda la acción a un sujeto competente, incrementan los riesgos de que el pequeño padezca graves consecuencias o incluso, secuelas irreversibles. Se convierten, por tanto, en ayudantes del antisujeto (enfermedad $\mathrm{o}$ afección) y/u oponentes del sujeto de acción ideal (personal sanitario cualificado).

Por último, (5) 'La confrontación entre prescriptores o consejeros (expertos versus industria)' nos permite detectar una extraña paradoja. Si bien las estructuras narrativas de este tipo de textos tienden a diferenciar constantemente ayudantes y oponentes de los padres en el cuidado del bebé como ciencia y creencia popular respectivamente, no es muy común la confrontación explícita entre profesionales de la medicina o investigadores acreditados y la industria asociada a la puericultura. Por lógica, las marcas comerciales de productos de alimentación, higiene y cuidado infantil que ocupan casi al 50\% las páginas de este tipo de publicaciones especializadas suelen presentarse en el rol de ayudantes (algo claramente definido en las "selecciones MIBB" de Mi bebé y yo). El único caso al que alude esta narrativa se centra en un tema recurrente como es el de la lactancia materna, los beneficios de la cual se especifican en tres planos -salud, bienestar emocional y material o pragmático-y se contraponen a los de la lactancia artificial, cuyo beneficio implícito, meramente económico, recae exclusivamente en la industria.

En las tablas que se adjuntan a continuación se ofrece sintéticamente una visión general de la distribución de estas estructuras semionarrativas, así como los restantes aspectos analizados, para cada una de las revistas familiares que conforman la muestra.

Tablas 3, 4 y 5. Cuadros analíticos: síntesis de resultados para cada una de las publicaciones

\begin{tabular}{|c|c|c|c|c|c|}
\hline \multicolumn{6}{|c|}{ EL MUNDO DE TU BEBÉ } \\
\hline \multirow[b]{2}{*}{ Texto } & \multicolumn{2}{|c|}{ Figuras enunciativas } & \multirow[b]{2}{*}{ Acto ilocutivo } & \multirow{2}{*}{$\begin{array}{c}\text { Estructura } \\
\text { semionarrativa }\end{array}$} & \multirow{2}{*}{$\begin{array}{c}\text { Competencias y motivaciones } \\
\text { de los roles principales }\end{array}$} \\
\hline & $\begin{array}{c}\text { Enunciador / } \\
\text { Narrador }\end{array}$ & $\begin{array}{c}\text { Enunciatario / } \\
\text { Narratario } \\
\end{array}$ & & & \\
\hline $\begin{array}{l}\text { Dar el pecho, ganar } \\
\text { en salud }\end{array}$ & $\begin{array}{l}\text { Revista / Pediatra } \\
\text { (mujer) }\end{array}$ & Madre & $\begin{array}{l}\text { Asertivo / } \\
\text { Expresivo }\end{array}$ & $\begin{array}{l}\text { (5) Confrontación entre } \\
\text { prescriptores }\end{array}$ & $\begin{array}{l}\text { Experto: quiere, puede y sabe } \\
\text { defender los beneficios de la } \\
\text { lactancia materna } v s \text { artificial }\end{array}$ \\
\hline $\begin{array}{l}\text { Los secretos de un } \\
\text { feliz descanso }\end{array}$ & $\begin{array}{l}\text { Revista / } \\
\text { Neonatóloga }\end{array}$ & $\begin{array}{l}\text { Cualquiera / padres, } \\
\text { "madre" }\end{array}$ & Asertivo & $\begin{array}{l}\text { (1) Experto que orienta a } \\
\text { los padres } \\
+ \text { c. Ayuda: Personal } \\
\text { sanitario } \\
+ \text { d. Opone: } \\
\text { Circunstancias }\end{array}$ & $\begin{array}{l}\text { Madre: puede (capacidad } \\
\text { fisiológica), y se infiere quiere } \\
\text { y debe ayudar al neonato } \\
\text { prematuro. } \\
\text { Experto: provee el saber } \\
\text { necesario }\end{array}$ \\
\hline \multirow[b]{2}{*}{$\begin{array}{l}\text { ¿Necesita comerlo } \\
\text { todo triturado? }\end{array}$} & \multirow[b]{2}{*}{$\begin{array}{l}\text { Revista / } \\
\text { Nutricionista } \\
\text { (mujer) }\end{array}$} & \multirow[b]{2}{*}{ Madre } & \multirow[b]{2}{*}{$\begin{array}{l}\text { Asertivo / } \\
\text { Directivo }\end{array}$} & $\begin{array}{l}\text { (1) Experto que orienta a } \\
\text { los padres }\end{array}$ & \multirow{2}{*}{$\begin{array}{l}\text { Madre: quiere y debe ayudar al } \\
\text { bebé en el proceso de } \\
\text { masticación, pero no sabe } \\
\text { cómo (obliga, ridiculiza, no } \\
\text { respeta al bebé) y/o no puede } \\
\text { (le falta paciencia, manifiesta } \\
\text { temores e inseguridad). } \\
\text { Experto: provee saber sobre el } \\
\text { modo adecuado y los rasgos a } \\
\text { potenciar. }\end{array}$} \\
\hline & & & & $\begin{array}{l}\text { (2) El desarrollo natural } \\
\text { del bebé: padres } \\
\text { oponentes o ayudantes }\end{array}$ & \\
\hline \multirow{2}{*}{$\begin{array}{l}\text { Los bebés más } \\
\text { vulnerables }\end{array}$} & $\begin{array}{l}\text { Revista / Psicóloga } \\
\text { infantil }\end{array}$ & $\begin{array}{l}\text { Padres / } \\
\text { "Mamá" }\end{array}$ & $\begin{array}{l}\text { Asertivo / } \\
\text { Directivo }\end{array}$ & $\begin{array}{l}\text { (1) Experto que orienta a } \\
\text { los padres }\end{array}$ & $\begin{array}{l}\text { Padres: saben detectar qué es } \\
\text { normal y quieren hacer lo que } \\
\text { deben (rutina) } \\
\text { Experto: sanción positiva }\end{array}$ \\
\hline & & & & $\begin{array}{l}\text { (2) El desarrollo natural } \\
\text { del bebé: padres } \\
\text { oponentes o ayudantes }\end{array}$ & $\begin{array}{l}\text { Padres: saben que deben } \\
\text { respetar los deseos y } \\
\text { necesidades del bebé pero no } \\
\text { quieren hacerlo (se resisten). } \\
\text { Experto: sanción negativa }\end{array}$ \\
\hline
\end{tabular}




\begin{tabular}{|c|c|c|c|c|c|}
\hline \multicolumn{6}{|c|}{ SER PADRES } \\
\hline \multirow[b]{2}{*}{ Texto } & \multicolumn{2}{|c|}{ Figuras enunciativas } & \multirow[b]{2}{*}{ Acto ilocutivo } & \multirow{2}{*}{$\begin{array}{c}\text { Estructura } \\
\text { semionarrativa }\end{array}$} & \multirow{2}{*}{$\begin{array}{l}\text { Competencias y motivaciones de los } \\
\text { roles principales }\end{array}$} \\
\hline & $\begin{array}{c}\text { Enunciador/ } \\
\text { Narrador }\end{array}$ & $\begin{array}{c}\text { Enunciatario / } \\
\text { Narratario }\end{array}$ & & & \\
\hline $\begin{array}{l}\text { Un desarrollo } \\
\text { espectacular }\end{array}$ & Revista / --- & $\begin{array}{l}\text { Padres. Aunque } \\
\text { "madre" en } \\
\text { imagen }\end{array}$ & $\begin{array}{l}\text { Declara- cional } \\
\text { / Directivo }\end{array}$ & $\begin{array}{l}\text { (2) El desarrollo } \\
\text { natural del bebé: } \\
\text { padres oponentes o } \\
\text { ayudantes }\end{array}$ & $\begin{array}{l}\text { Bebé: sabe, quiere y puede sobrevivir } \\
\text { gracias a sus rasgos físicos (inspira } \\
\text { ternura; seducción) y su capacidad de } \\
\text { desarrollo } \\
\text { Padres: no saben cómo se desarrollan los } \\
\text { bebés normalmente y no pueden actuar (si } \\
\text { están nerviosos), pero deben ser ayudantes } \\
\text { eficientes. } \\
\text { Experto: provee el saber necesario (qué } \\
\text { hacer: estimular, no prohibir) y los } \\
\text { tranquiliza (ayuda) }\end{array}$ \\
\hline Lactancia materna & Revista / --- & Madre & $\begin{array}{l}\text { Asertivo / } \\
\text { Directivo }\end{array}$ & $\begin{array}{l}\text { (1) Experto que } \\
\text { orienta a los padres } \\
+ \text { c. Ayuda: } \\
\text { Naturaleza (instinto } \\
\text { del bebé)/ } \\
\text { productos } \\
+ \text { d. Opone: Mitos y } \\
\text { normas rígidas de la } \\
\text { sociedad }\end{array}$ & $\begin{array}{l}\text { Madre: quiere y puede dar el pecho } \\
\text { (capacidad física) aunque no sabe de qué } \\
\text { es capaz (temor). } \\
\text { Experto: certifica sus capacidades; } \\
\text { minimiza el efecto de los oponentes; y } \\
\text { provee saber sobre ayudantes. }\end{array}$ \\
\hline $\begin{array}{l}\text { ¡Me gusta la } \\
\text { verdura! }\end{array}$ & $\begin{array}{l}\text { Revista / Padres } \\
\text { (cocinero) }\end{array}$ & Padres & Expresivo & $\begin{array}{l}\text { (1) Experto que } \\
\text { orienta a los padres }\end{array}$ & $\begin{array}{l}\text { Padre como experto: provee saber (cómo } \\
\text { cocinar verdura para niños). } \\
\text { Padres como asesorados: no saben y no } \\
\text { pueden (falta paciencia e imaginación), } \\
\text { pero quieren y deben }\end{array}$ \\
\hline $\begin{array}{l}\text { Bienvenido a casa, } \\
\text { bebé }\end{array}$ & Revista / --- & $\begin{array}{l}\text { Padres / } \\
\text { "Mamá" y } \\
\text { lactancia } \\
\text { "Papá" y tareas a } \\
\text { no olvidar }\end{array}$ & $\begin{array}{l}\text { Expresivo / } \\
\text { Directivo }\end{array}$ & $\begin{array}{l}\text { (1) Experto que } \\
\text { orienta a los padres } \\
\text { + a. Beneficios para } \\
\text { los padres: beneficio } \\
\text { vivencial y pasional } \\
\text { (placer, ternura, } \\
\text { alegría de vivir) }\end{array}$ & $\begin{array}{l}\text { Padres: quieren y deben cuidar y proteger } \\
\text { al bebé (y hacérselo saber), no pueden si } \\
\text { no confian en los instintos (del bebé más } \\
\text { que propios). } \\
\text { Experto: provee saber necesario } \\
\text { + Sanción negativa: retribución (crueldad: } \\
\text { dejar llorar) }\end{array}$ \\
\hline Leche en biberón & Revista / --- & Padres & Asertivo & $\begin{array}{l}\text { (1) Experto que } \\
\text { orienta a los padres }\end{array}$ & $\begin{array}{l}\text { Padres: no saben y/o no quieren, aunque } \\
\text { pueden y deben actuar correctamente } \\
\text { (retirar biberón) para evitar perjudicar al } \\
\text { bebé (obesidad, caries; dependencia } \\
\text { emocional) } \\
\text { Experto: provee saber necesario y exhorta } \\
\text { a corregirse a los padres (manipulación } \\
\text { contractual: amenaza) }\end{array}$ \\
\hline $\begin{array}{l}\text { Dormir bien: } \\
\text { tus cartas al } \\
\text { especialista }\end{array}$ & $\begin{array}{l}\text { Revista / Experto } \\
\text { (médico) }\end{array}$ & $\begin{array}{l}\text { Madre } \\
\text { (demandante } \\
\text { mayoritaria) }\end{array}$ & $\begin{array}{l}\text { Expresivo / } \\
\text { Directivo }\end{array}$ & $\begin{array}{l}\text { (5) Confrontación } \\
\text { entre prescriptores }\end{array}$ & $\begin{array}{l}\text { Experto médico (ciencia): sabe, puede, } \\
\text { quiere y debe ayudar a los padres en la } \\
\text { crianza de los hijos. } \\
\text { "Otras personas" (saber popular): no saben } \\
\text { (carecen de conocimiento válido) y no } \\
\text { pueden (carecen de medios) ayudarlos } \\
\text { aunque quieran. }\end{array}$ \\
\hline
\end{tabular}




\begin{tabular}{|c|c|c|c|c|c|}
\hline \multicolumn{6}{|c|}{ MI BEBÉ Y YO } \\
\hline \multirow[b]{2}{*}{ Texto } & \multicolumn{2}{|c|}{ Figuras enunciativas } & \multirow[b]{2}{*}{$\begin{array}{l}\text { Acto } \\
\text { ilocutivo }\end{array}$} & \multirow[b]{2}{*}{$\begin{array}{l}\text { Estructura } \\
\text { semionarrativa }\end{array}$} & \multirow[b]{2}{*}{$\begin{array}{c}\text { Competencias y motivaciones de los roles } \\
\text { principales }\end{array}$} \\
\hline & $\begin{array}{l}\text { Enunciador/ } \\
\text { Narrador }\end{array}$ & $\begin{array}{l}\text { Enunciatario } \\
\text { / Narratario }\end{array}$ & & & \\
\hline $\begin{array}{l}\text { Pequeño ¿cuánto } \\
\text { roncas? }\end{array}$ & Revista / --- & Padres & $\begin{array}{l}\text { Asertivo / } \\
\text { Directivo }\end{array}$ & $\begin{array}{l}\text { (1) Experto que } \\
\text { orienta a los padres } \\
+(5) \text { Confrontación } \\
\text { entre prescriptores } \\
\text { (creencias sin } \\
\text { fundamento; } \\
\text { conocimiento } \\
\text { científico válido) }\end{array}$ & $\begin{array}{l}\text { Padres: deben cuidar al bebé pero no saben } \\
\text { cómo hacerlo adecuadamente } \\
\text { Experto: provee saber necesario y remite al } \\
\text { asesoramiento profesional. } \\
\text { Manipulación contractual: amenaza (culpa } \\
\text { y miedo a las consecuencias de una apnea } \\
\text { no detectada) }\end{array}$ \\
\hline $\begin{array}{l}\text { Tiene un ojo } \\
\text { perezoso }\end{array}$ & Revista / --- & Padres & Directivo & $\begin{array}{l}\text { (1) Experto que } \\
\text { orienta a los padres } \\
+(5) \text { Confrontación } \\
\text { entre prescriptores } \\
+ \text { c. Ayuda: Padres } \\
\text { compet. } \\
+ \text { d. Opone: Padres } \\
\text { incompet. }\end{array}$ & $\begin{array}{l}\text { Padres: deben cuidar al bebé pero no saben } \\
\text { cómo hacerlo adecuadamente } \\
\text { Experto: provee saber necesario para } \\
\text { reconocerse como un padre competente o no } \\
\text { (y dirigirse al profesional). } \\
\text { Manipulación contractual: amenaza (culpa } \\
\text { y miedo a las consecuencias de una } \\
\text { ambliopía no tratada) }\end{array}$ \\
\hline $\begin{array}{l}\text { Displasia de cadera / } \\
\text { Cuidado con el pipi }\end{array}$ & Revista / --- & Madre & Asertivo & $\begin{array}{l}\text { (1) Experto que } \\
\text { orienta a los padres } \\
\text { (como ayudantes o } \\
\text { destinadores } \\
\text { contrato de sujetos } \\
\text { competentes) }\end{array}$ & $\begin{array}{l}\text { Padres: deben proteger y cuidar al bebé } \\
\text { aunque no pueden hacerlo adecuadamente } \\
\text { en aquellas cuestiones médicas que ignorar } \\
\text { (no saben) } \\
\text { Experto: provee saber necesario y remite a } \\
\text { la responsabilidad de la neonatóloga en la } \\
\text { detección precoz. }\end{array}$ \\
\hline $\begin{array}{l}\text { ¿Cuántas tomas son } \\
\text { necesarias? }\end{array}$ & Revista / --- & Madre & $\begin{array}{l}\text { Directivo / } \\
\text { Expresivo }\end{array}$ & $\begin{array}{l}\text { (1) Experto que } \\
\text { orienta a la madre } \\
\text { + c. Ayuda: } \\
\text { Naturaleza (instinto } \\
\text { del bebé)/ } \\
\text { productos } \\
\text { + d. Opone: Mitos y } \\
\text { normas rígidas de la } \\
\text { sociedad }\end{array}$ & $\begin{array}{l}\text { Madre: quiere y debe cuidar al bebé, puede } \\
\text { hacerlo si "confian en él" y sabe interpretar } \\
\text { sus necesidades. } \\
\text { Bebé: destinador contrato y sujeto de } \\
\text { estado. }\end{array}$ \\
\hline Sus primeros purés & Revista / --- & Padres & $\begin{array}{l}\text { Asertivo / } \\
\text { Directivo }\end{array}$ & $\begin{array}{l}\text { (1) Experto que } \\
\text { orienta a los padres } \\
+ \text { c. Ayuda: } \\
\text { Productos } \\
\text { comerciales } \\
\end{array}$ & $\begin{array}{l}\text { Experto: quiere proveer a los padres de } \\
\text { saberes en torno a productos y pautas } \\
\text { alimenticias que los ayuden en su misión de } \\
\text { crianza. }\end{array}$ \\
\hline \multirow{3}{*}{$\begin{array}{l}\text { ¿Es un caprichoo } \\
\text { una necesidad? }\end{array}$} & \multirow{3}{*}{ Revista / --- } & \multirow{3}{*}{ Madre } & \multirow{3}{*}{$\begin{array}{l}\text { Directivo / } \\
\text { Expresivo }\end{array}$} & $\begin{array}{l}\text { (1) Experto que } \\
\text { orienta a los padres } \\
\text { + a. Beneficios para } \\
\text { los padres: vivencial } \\
\text { (tranquilidad y } \\
\text { felicidad compartida } \\
\text { - necesidades) }\end{array}$ & $\begin{array}{l}\text { Madre: quiere y debe cuidar y proteger al } \\
\text { bebé pero no sabe distinguir cuando debe } \\
\text { ceder o no a sus demandas. } \\
\text { Experto: provee el saber imprescindible } \\
\text { para afrontar el reto (reconocer } \\
\text { necesidades). }\end{array}$ \\
\hline & & & & $\begin{array}{l}\text { (4) Padres que } \\
\text { perjudican al bebé }\end{array}$ & \\
\hline & & & & $\begin{array}{l}\text { (3) Explicita: La } \\
\text { sumisión de los } \\
\text { padres a las } \\
\text { demandas del bebé: } \\
\text { deber y } \\
\text { compensación, las } \\
\text { claves de la } \\
\text { felicidad }\end{array}$ & $\begin{array}{l}\text { En el caso de caprichos (demandas } \\
\text { negadas), la madre debe compensar el } \\
\text { perjuicio emocional causado al bebé } \\
\text { (frustración) al proteger su integridad física. }\end{array}$ \\
\hline $\begin{array}{l}\text { Cómo ser una } \\
\text { mamá-guardería }\end{array}$ & Revista / --- & Madres & Asertivo & $\begin{array}{l}\text { (1) Experto que } \\
\text { orienta a los padres } \\
\text { + a. Beneficios para } \\
\text { los padres } \\
\text { (profesional y } \\
\text { cliente): beneficio } \\
\text { vivencial }\end{array}$ & $\begin{array}{l}\text { Madre: quiere ser mamá-guardería. } \\
\text { Experto: provee saber necesario sobre } \\
\text { requisitos de formación (saberes a adquirir) } \\
\text { y recursos espaciales (para poder } \text { ejercer). }\end{array}$ \\
\hline
\end{tabular}




\begin{tabular}{|c|c|c|c|c|c|}
\hline $\begin{array}{l}10 \text { dudas sobre la } \\
\text { fiebre }\end{array}$ & $\begin{array}{l}\text { Revista / Experto } \\
\text { (médico) }\end{array}$ & Padres (mamá) & Asertivo & $\begin{array}{l}\text { (1) Experto que } \\
\text { orienta a los padres } \\
\text { + c. Ayuda: Médico } \\
\text { especial. }\end{array}$ & $\begin{array}{l}\text { Padres: quieren cuidar a sus hijos } \\
\text { (preocupados) pero no saben suficiente } \\
\text { sobre la fiebre. } \\
\text { Experto: provee saber necesario }\end{array}$ \\
\hline $\begin{array}{l}\text { ¿Es alérgico a la } \\
\text { leche de vaca? }\end{array}$ & Revista / --- & Padres (mamá) & Asertivo & $\begin{array}{l}\text { (1) Experto que } \\
\text { orienta a los padres } \\
\text { + d. Opone: exceso } \\
\text { de información no } \\
\text { fiable }\end{array}$ & $\begin{array}{l}\text { Padres: no saben lo que deberían (víctimas } \\
\text { de fuentes de información confusas) y } \\
\text { quieren proteger a sus hijos. } \\
\text { Experto: provee saber para poder exigir a } \\
\text { sujetos competentes (médico) las pruebas } \\
\text { pertinentes. }\end{array}$ \\
\hline $\begin{array}{l}\text { Lactancia materna: } \\
\text { ¿Das el pecho? } \\
\text { Puedes comer de } \\
\text { todo }\end{array}$ & Revista / --- & Madres & $\begin{array}{l}\text { Asertivo / } \\
\text { Directivo }\end{array}$ & $\begin{array}{l}\text { (1) Experto que } \\
\text { orienta a los padres } \\
\text { + c. Ayuda: instinto } \\
\text { / médico }\end{array}$ & $\begin{array}{l}\text { Madre: quiere y debe cuidar al bebé, puede } \\
\text { hacerlo si "sigues su instinto" al alimentarse } \\
\text { y sabe interpretar qué perjudica al pequeño. } \\
\text { Experto: orienta su conducta, pero la remite } \\
\text { al médico en la toma de decisiones (sujeto } \\
\text { incompetente) }\end{array}$ \\
\hline $\begin{array}{l}\text { Yogur: ;cuántos } \\
\text { beneficios! }\end{array}$ & Revista / --- & Padres & $\begin{array}{l}\text { Asertivo / } \\
\text { Directivo }\end{array}$ & $\begin{array}{l}\text { (1) Experto que } \\
\text { orienta a los padres } \\
+c \text {. Ayuda: } \\
\text { Productos } \\
\text { comerciales }\end{array}$ & $\begin{array}{l}\text { Experto: quiere proveer a los padres de } \\
\text { saberes en torno a productos y pautas } \\
\text { alimenticias que los ayuden en su misión de } \\
\text { crianza. }\end{array}$ \\
\hline $\begin{array}{l}\text { Música para la } \\
\text { mente y el corazón }\end{array}$ & Revista / --- & Padres (mamá) & $\begin{array}{l}\text { Asertivo / } \\
\text { Directivo }\end{array}$ & $\begin{array}{l}\text { (1) Experto que } \\
\text { orienta a los padres } \\
\text { + a. Beneficios para } \\
\text { los padres: beneficio } \\
\text { vivencial }\end{array}$ & $\begin{array}{l}\text { Padres: quieren cuidar a sus hijos de la } \\
\text { mejor manera posible pero no saben los } \\
\text { beneficios de la música. } \\
\text { Experto: provee este saber (competencial) } \\
\text { Bebé: sujeto con competencias físicas, } \\
\text { emocionales y cognitivas a adquirir. }\end{array}$ \\
\hline $\begin{array}{l}\text { Máxima higiene en } \\
\text { el hogar }\end{array}$ & Revista / --- & $\begin{array}{l}\text { Padres (mamá en } \\
\text { imagen) }\end{array}$ & $\begin{array}{l}\text { Asertivo / } \\
\text { Directivo }\end{array}$ & $\begin{array}{l}\text { (1) Experto que } \\
\text { orienta a los padres } \\
\text { +c. Ayuda: } \\
\text { Productos } \\
\text { comerciales }\end{array}$ & $\begin{array}{l}\text { Padres: quieren y deben proteger a sus hijos } \\
\text { del ataque de gérmenes y bacterias. } \\
\text { Experto: provee saber sobre productos de } \\
\text { limpieza que puedan ayudar a cumplir la } \\
\text { misión. }\end{array}$ \\
\hline
\end{tabular}

El predominio de la narración prototípica (1) 'experto que orienta a los padres en el cuidado del bebé' es un rasgo compartido por las tres publicaciones. Mi bebé y yo es la revista familiar con un discurso más homogéneo en cuanto a estructuras semionarrativas: los padres deben y quieren llevar a cabo las tareas de crianza y cuidado de sus hijos, pero requieren de la revista como experto que les provee los conocimientos necesarios para llevarlo a cabo. En cuestiones médicas, emerge la confrontación entre especialistas reconocidos y otras fuentes (mitos y normas rígidas de la sociedad, exceso de información de dudosa validez científica, etc.), pero, a diferencia de El mundo de tu bebé, convierte a los productos comerciales (alimentación e higiene) en los aliados necesarios de los padres. Esta publicación también introduce la estructura semionarrativa alterna donde se presupone a los padres ayudantes u oponentes del desarrollo natural del bebé en función de sus competencias.

Pese a observar inicialmente el modelo canónico de la narración (contrato, competencia, ejecución y sanción) las fases de ejecución y sanción tienen un peso reducido, cuando no nulo. Los textos objeto de estudio centran su acción en orientar o prescribir la acción de los padres y en dotarlos de capacidades para cumplir sus objetivos de manera eficiente, y tan sólo de manera inferida se proponen como sancionadores de las acciones previamente realizadas. Es decir, no ejercen el rol de jueces o evaluadores de la conducta habitual de los padres, sino el de tutores o mentores de sus acciones futuras.

En general, los padres y en especial, la madre, se presentan como sujetos de acción que tienen la voluntad y asumen la responsabilidad de cuidar y proteger a sus peque- 
ños, pero carecen de los conocimientos necesarios para llevar a cabo esta misión. Las revistas promueven el asesoramiento y/o la prescripción de expertos que realizan acciones competenciales: informan o instan a superar temores e inseguridades.

En el plano de la enunciación se distingue El mundo de tu bebé por la construcción de una doble instancia enunciativa, al multiplicar las voces que actúan como expertos delegados por la revista. Se dirige abiertamente a la madre, en actos comunicativos de tipo asertivo donde se combina un tono informativo con cierta tendencia a la sanción negativa como forma de amenaza o apelación al temor de los padres a no actuar correctamente. En cambio, tanto Ser padres como Mi bebé y yo simplifican la enunciación al aplicar un tratamiento homogéneo de los textos, como una voz única no personificada. Les corresponde una enunciataria diversificada, donde pese al uso indistinto de los padres como narratario más común, prevalece la figura materna ya sea en alusiones específicas en el cuerpo del texto o en la representación gráfica. Aunque, mientras que Ser padres tiende a construir textos de carácter más opinativo o en un estilo protector e inclusivo condescendiente, con el que minimiza la sanción negativa y sustituye el recurso a la amenaza por la promesa, Mi bebé y yo es la revista familiar de estilo más autoritario y coercitivo para con sus lectores modelos, padres y sobretodo, la madre, sobre la que recaen el grueso de sus actos ilocutivos directivos.

\section{Discusión y conclusiones}

A partir de los resultados y análisis presentados en el apartado anterior, vemos de qué manera el ejercicio de maternidad se distingue del genérico de la «parentalidad» con un peso específico incuestionable pero ahora en tensión -cuando no en franca contradicción-, ante una emergencia tanto en su forma (ensalzamiento de la figura de la mujer-madre) como en su fondo (una manera de ejercer la maternidad que requiere atención exclusiva y unas dotes emocionales que se presentan como exclusivas de las mujeres). De alguna manera, parece haber un resurgimiento del valor inherente al espacio privado (frente a las luchas que se dan en el espacio público) a través de la idealización de una maternidad entendida como «dedicación exclusiva e intransferible», lo que puede derivar en una nueva trampa de culpa sutil para muchas mujeres que quieran desempeñarse en el espacio público-profesional, a la vez que quieran ser madres. Las bajas por maternidad/paternidad, las jornadas reducidas o las conciliaciones laborales son mayores entre las mujeres que entre los hombres. Conviene matizar que, por supuesto, no siempre se trata de una elección voluntaria y libre; es de sobras conocida la doble jornada laboral de las madres trabajadoras que, una vez finalizada su dedicación a la jornada laboral-pública, continúan trabajando dentro del espacio familiar sin que se reconozca esta dedicación como un trabajo. Sin embargo, comienzan a consolidarse voces que no contemplan la dedicación al mundo de lo público a la manera que la etapa industrial necesitó construir como modelo de identificación: el trabajo como escenario de la auténtica realización personal, el éxito económico como auténtica moneda de valoración social, la opción por la carrera profesional como señal de autonomía, independencia y madurez social. ... Para muchas mujeres, combinar un trabajo a media jornada con estar en casa comienza a ser la manera de sentirse realizadas o, como mínimo no culpables, más allá de los discursos del poder (Beck-Gerns- 
heim, 2003; Ferry, 2008; Touraine, 2005). Aunque esta desculpabilización ha sido únicamente posible para las mujeres de las clases medias puesto que las madres de las clases trabajadoras siempre han tenido que mantener la tensión entre el trabajo remunerado/espacio público y el no remunerado/espacio privado (Hays, 1998).

Estudios previos (Aler, 2006) demuestran la clara tendencia en la sociedad española a una tecnificación de los procesos de embarazo, parto y crianza. Asimismo, el trabajo de la autora ha detectado 7 temores de las mujeres que se plantean ser madres: 1) el miedo a transformarse en madres; 2) desconfianza en la sabiduría popular; 3) soledad, aislamiento y estrés; 4) entreguismo al sistema de expertos; 5) carencia de espacios sociales adecuados; 6) escisión pervertida de prioridades vitales; y 7) reproducción social de relaciones filiales patológicas. En el diálogo entre los contenidos mediáticos y la realidad social, se requiere del lector una cierta activación de la función de referencialidad. Sea a través de la presencia de determinados modelos de mujer-madre como por su notoria ausencia -a través de mecanismos de invisibilidad igualmente potentes- el reconocimiento de esos modelos o maneras de ser madre se ve potenciado a través de los mecanismos de identificación de la lectora (recurrencia) o, en términos más amplios, por el reconocimiento de un universo socialmente compartido. Convenimos con otros trabajos (Viñas, 2003) en que el modelo de maternidad que se comprueban en las revistas analizadas se asemeja a una auténtica «carrera de obstáculos» en la que la madre debe tener un conocimiento amplio de disciplinas distintas (pediatría, psicología, alimentación infantil, etc.) al servicio todo ello de la cultura patriarcal tradicional.

Desde el periodismo especializado se ha considerado este tipo de publicaciones como periodismo de servicio, en el sentido que se trata de un periodismo que orienta al lector. Pero un periodismo que los mismos especialistas consideran que tiene sus contrapartidas. Por ejemplo, el hecho de privar a las madres de las estructuras de socialización no profesionalizadas (familia, amigas, conocidas) como orientación válida y sustituirla por el personal cualificado las aboca a una definición de sujetos incompetentes o siempre carentes de conocimientos, conocimientos que pertenecen al ámbito científico y que están en permanente actualización.

¿No implica el servicio una reducción en la capacidad de abstracción del individuo, un debilitamiento de su poder decisorio, urgido como está a tomar decisiones rápidas, en un medio sobrecargado de información confusa y dispersa, más proclive a provocar dudas que a generar satisfacciones? ¿No supondrá un tratamiento paternalista que, en último extremo, lleve a una dependencia de ese lector-consumidor hacia el medio, al que entrega su confianza? (Diezhandino, 1994: 107).

El peligro de tratar el hecho a partir de una historia humana es substituir la dimensión global del mismo por un enfoque parcial y personal que diluye del acontecimiento los procesos políticos, las relaciones de poder o las fuerzas económicas (Diezhandino, 1994). La contrapartida es el desinterés por los asuntos colectivos. El tono intimista de esta prensa no contribuye a este sentimiento participación en un colectivo con unas necesidades y problemáticas comunes, es como si se dirigiera a cada una de las lectoras individualmente, "no hay pues ninguna posibilidad de convertir el problema «personal» en "social»"(Gallego, 1990: 54). Aun cuando el «nosotras» une 
las lectoras y crea una ilusión de grupo con iguales aspiraciones, la realidad es que «aísla». El uso de este «nosotras» no es ideológico ni pretende crear conciencia de situaciones de desigualdad y, por lo tanto, de grupo, sino que se convierte en una estrategia más para conseguir identificación y, consecuentemente, consumo (Feliu de la Garza et al., 1999). Como consecuencia de todo ello, pese a estas estrategias discursivas para crear proximidad, si no se cuestionan los roles tradicionales de las mujeres lo que acaban haciendo es perpetuar la actual situación.

\section{Referencias bibliográficas}

ABRIL, Natividad (1995): "Las categorías sexo/género en la construcción del discurso periodístico". En: ORTEGA LÓPEZ, Margarita (Ed.): Las mujeres en la opinión pública, pp. 151-162. Madrid, Instituto Universitario de Estudios de la Mujer, Universidad Autónoma de Madrid.

ALER, Isabel (2006): La transformación de la maternidad en la sociedad española 1975-2005. Otra visión sociológica. Sevilla, Fundación Centro de Estudios Andaluces

ARIÈS, Philippe (1987): El niño y la vida familiar en el Antiguo Régimen. Madrid, Taurus.

BADINTER, Elisabeth (2011): La mujer y la madre. Madrid, La esfera de los libros.

BAUMAN, Zygmunt (2007): Vida de consumo. Madrid, Fondo de Cultura Económica.

BAUMAN, Zygmunt (2005): Amor Líquido. Acerca de la fragilidad de los vínculos humanos. Buenos Aires, Fondo de Cultura Económica.

BECK, Ulrich \& BECK-GERNSHEIM, Elisabeth (2003): La individualización. El individualismo institucionalizado y sus consecuencias sociales y políticas. Barcelona, Paidós.

BECK, Ulrich \& BECK-GERNSHEIM, Elisabeth (1990): El normal caos del amor. Las nuevas formas de la relación amorosa. Barcelona, Paidós.

BECK-GERNSHEIM, Elisabeth (2003): La reinvención de la familia. En busca de nuevas formas de convivencia. Barcelona, Paidós.

BEAUGRANDE, Robert Alain \& DRESSLER, Wolfang Ulrich (1997): Introducción a la lingüistica del texto. Madrid, Ariel.

CASTILLA, M ${ }^{a}$ Victoria (2009): "Individualización, dilemas de la maternidad y desarrollo laboral: continuidades y cambios". Intersecciones en antropología, 10 (2), 343-358.

COURTÉS, Jean (1997): Análisis semiótico del discurso: del enunciado a la enunciación. Madrid, Gredos.

DIEZHANDINO, Ma Pilar (1994): Periodismo de servicio: La utilidad como complemento informativo en Times, Newsweek y US World Report y unos apuntes del caso español. Barcelona, Bosch. 
FAGOAGA, Concha (1985): ¿Por qué las mujeres no leen periódicos? Mujeres, 6.

FAIRCLOUGH, Norman (2003): Analysing Discourse. Textual Analysis for Social Research. New York, Routledge Taylor \& Francis.

FELIU, Elena; De la GARZA, Ma Luisa et al. (1999): "Decálogos comunicativos para la nueva mujer. El papel de las revistas femeninas en la construcción de la feminidad". Discurso y Sociedad, 1(3), 31-72.

FERRY, Luc (2008): Familia y amor. Un alegato a favor de la vida privada. Madrid, Taurus.

FIGUERAS, Mònica (2005): Premsa juvenil femenina i identitat cultural, Tesis Doctoral, Diponible en e-repositorio UPF: http://www.tdx.cat/bitstream/handle $/ 10803 / 7519 / \mathrm{tmfm} 1$ de $1 . p d f ?$ sequence $=1$

GALLEGO, Joana (1990): Mujeres de papel. De ;Hola! a Vogue: la prensa femenina en la actualidad. Barcelona, Icaria.

GIDDENS, Anthony (2000): La transformación de la intimidad. Sexualidad, amor y erotismo en las sociedades modernas. Madrid, Càtedra.

GREIMAS, Algirdas Julien (1990): Narrative semiotics and cognitive discourses. London, Pinter.

HAYS, Sharon (1998): Las contradicciones culturales de la maternidad. Barcelona, Paidós.

ILLOUZ, Eva (2008): Saving the modern soul. Therapy, emotions, and the culture of self-help. Berkeley, University of California Press.

HOCHSCHILD, Arlie R. (2008): La mercantilización de la vida intima. Apuntes de la casa y el trabajo. Madrid, Katz Editores.

LIPOVETSKY, Gilles (2006): Los tiempos hipermodernos. Barcelona, Anagrama.

PERICOT, Jordi (2002): Mostrar para decir, la imagen en contexto. Barcelona, Aldea Global.

PERINAT, Adolfo y MARRADES, $\mathrm{M}^{\mathrm{a}}$ Isabel (1980): Mujer, prensa y sociedad en España. 1800-1939. Madrid, Centro de Investigaciones Sociológicas.

RUIZ COLLANTES, Xavier; OBRADORS, Matilde; PUJADAS, Eva; y PÉREZ, Oliver (2011): "Qualitative-quantitative analysis of narrative structures: The narrative roles of immigrants in Spanish television series". Semiotica, 184 (1/4), 99121.

RUIZ COLLANTES, Xavier; FERRÉS, Joan; OBRADORS, Matilde; et al. (2006): "La imatge pública de la immigració en les sèries de televisió". Quaderns del CAC, 23-24, 103-126.

SEGURA, Isabel \& SELVA, Marta (1984). Revistes de dones 1846-1935. Barcelona, Edhasa. 
TITSCHER, Stefan; MEYER, Michael; WODAK, Ruth; \& VETTER, Eva (2000): Methods of Text and Discourse Analysis. In Search of Meaning. London, Thousand Oaks.

TOURAINE, Alain (2005): Un nuevo paradigma para comprender el mundo de hoy. Barcelona, Paidós.

VIÑAS, Dolores (2003): "Nuevos modelos de maternidad". VI Trobada de comares de la comunitat valenciana. Qualitat per a la dona davant el nou mil.leni. Conselleria de Sanitat, Generalitat Valenciana, pp. 41-51. Disponible en: http://publicaciones.san.gva.es/publicaciones/documentos/V.2369-2003.pdf\#page $=42$ 